OPEN ACCESS

Edited by: Balwinder Singh Mayo Clinic, United States

Reviewed by:

Kabirullah Lutfy,

Western University of Health

Sciences, United States

Stefania Schiavone,

University of Foggia, Italy

*Correspondence:

Zhaoyu Gan

moyanchou@163.com

tThese authors have contributed equally to this work

Specialty section:

This article was submitted to

Psychopharmacology,

a section of the journal

Frontiers in Psychiatry

Received: 26 January 2020 Accepted: 18 November 2020 Published: 08 January 2021

Citation:

Li K, Liao Y, Yang Z, Yang C, Chen $M$, Wu X and Gan Z (2021) Case Report:

Paliperidone Palmitate in the Management of Bipolar I Disorder With Non-compliance. Front. Psychiatry 11:529672. doi: 10.3389/fpsyt.2020.529672

\section{Case Report: Paliperidone Palmitate in the Management of Bipolar I Disorder With Non-compliance}

\author{
Kanglai Li ${ }^{1+}$, Yingtao $\mathrm{Liao}^{2+}$, Zhihua Yang ${ }^{2}$, Caishuang $\mathrm{Yang}^{2}$, Minhua Chen $^{2}$, Xiuhua Wu ${ }^{2}$ \\ and Zhaoyu Gan ${ }^{2 *}$ \\ ${ }^{1}$ Very Important Patients Department, The Third Affiliated Hospital of Sun Yat-sen University, Guangzhou, China, \\ ${ }^{2}$ Department of Psychiatry, The Third Affiliated Hospital of Sun Yat-sen University, Guangzhou, China
}

Background: Medication non-adherence is prevalent in patients with bipolar disorder (BD). Long-acting injectable antipsychotics (LAIAs) are widely used to improve compliance with treatment. This study aimed to illustrate the effectiveness, compliance, and safety profile of once-monthly paliperidone palmitate (PP1M), a novel therapeutic LAIA, in the management of bipolar I disorder (BDI).

Method: A prospective follow-up was arranged to $11 \mathrm{BDI}$ patients who were prescribed PP1M as monotherapy or adjunctive treatment. Severity of symptoms, disturbing behavior, status of employment, 17-item Hamilton Depression Rating Scale (HAMD-17), and Young Mania Rating Scale (YMRS) were evaluated at the baseline and the endpoint of follow-up. Clinical Global Impression-Bipolar Disorder-Severity of IIIness Scale (CGI-BP) and Treatment Emergent Symptom Scale (TESS) were measured at each injection of PP1M. Compliance, relapse or switch, and new hospitalization were monitored through the period of follow-up.

Results: The median duration of treatment was 14 months, ranging from 5 to 22 months. The scores (mean \pm standard deviation) of HAMD-17, YMRS, and CGI-BP generally decreased from the baseline $(16.1 \pm 10.3,30.9 \pm 12.6,5.3 \pm 0.7)$ to the endpoint $(7.4 \pm 5.7,3.7 \pm 3.2,2.3 \pm 0.7)$. No disturbing behavior was detected at the endpoint. Neither new hospitalization nor manic/mixed episode occurred during treatment, whereas mild to moderate depressive episodes were reported in three cases. The status of employment of 10 participants (90.9\%) was improved, and no new safety concern was detected.

Conclusion: PP1M might offer a new valid treatment option in the long-term management of $\mathrm{BDI}$, especially for those with poor compliance with oral medication. However, more studies are needed to further justify such role.

Keywords: bipolar disorder, treatment, long-acting injectable antipsychotics, once-monthly paliperidone palmitate, non-compliance 


\section{INTRODUCTION}

Bipolar disorder (BD) is a common and disabling mental disorder, with a lifetime prevalence of $2.4 \%$ in the world (1). The pooled suicide rate in BD is as high as 164 per 100,000 personyears, accounting for $3.4-14 \%$ of all suicide death (2). Although the etiology of $\mathrm{BD}$ is not yet clear, long-term pharmaceutical treatment is still the most effective methods to ameliorate symptoms and prevent relapses and chronification. However, the high non-adherence rate ranging from 20 to $60 \%$ remains as a formidable challenge in the clinical practice for patients with $\mathrm{BD}$ (3). For BD patients with current major depressive episode (MDE), our previous report (4) has demonstrated that over $60 \%$ of treatment interruption occurred within 12 months after treatment initiation, and that over $40 \%$ of treatment discontinuation happened in the first 3 months. Medication non-adherence in BD not only is associated with high risk of recurrence, relapse, and hospitalization but also decreases the rate of remission and recovery $(5,6)$.

Long-acting injectable (LAI) drug is considered to be one of the most promising strategies to manage medication nonadherence in $\mathrm{BD}$, which has been shown to decrease the risk of suicide attempts and lower the mental health care expenditure $(7,8)$. Findings from real-world study suggest that LAI antipsychotics ensure a better medication adherence for patients with schizophrenia or BD than oral antipsychotics (9). However, few LAI second-generation antipsychotics have been approved for the treatment of BD currently. To date, only LAI risperidone and LAI aripiprazole have received approval by the Federal Drug Administration for this indication (3). As a long-active formulation of the active metabolite of risperidone, paliperidone palmitate (PP1M) has demonstrated its efficacy and safety in the long-term management of schizophrenia. Paliperidone extended-release (ER) has been proven to be effective and safe to treat acute manic or mixed episode, thus recommended by the 2018 Canadian Network for Mood and Anxiety Treatments (CANMAT) to be a first-line monotherapy option for initial mania treatment (10-12) and a second-line therapy option for maintenance treatment $(13,14)$. Oncemonthly PP1M, as monotherapy or adjunctive therapy, is also shown to significantly delay psychotic, depressive, and/or manic relapses in patients with schizoaffective disorders (15). That is to say, the efficacy of the chemical component of paliperidone in the management of bipolar I disorder (BDI) has been justified in previous studies.

Based on these facts, we hypothesize that PP1M is therapeutically promising in the long-term management of BDI. However, there are few evidences about PP1M in BDI patients. Thus, in this study, we followed up patients with BDI who were treated with PP1M, aiming to evaluating the effectiveness, compliance, and treatment-emergent adverse events (TEAEs) of PP1M among these cases.

\section{METHODS}

\section{Study Design and Subjects}

This was an open-label, one-arm, prospective observational study. All the participants in this study came from patients who sought medical help for BD at the psychiatric department of the Third Affiliated Hospital of Sun Yat-sen University between July 2017 and December 2018. The diagnosis of BD and mental comorbidities was made according to the Diagnostic and Statistical Manual of Mental Disorders, Fourth Edition, Text Revision (DSM-IV-TR) based on the subjects' history of present illness and routine mental examination. The inclusion criteria of this study were: (1) aged 16-65 years, (2) met the DSM-IVTR criteria for BDI, (3) responded well and had good tolerance to oral risperidone or paliperidone ER treatment, and 4) had a history of non-compliance with oral psychopharmaceutical treatment or claimed unwilling to take oral medication every day or having difficulty in complying with oral psychopharmaceutical treatment after being discharged from hospital. Participants who had one of the following conditions were excluded: (1) unable or refused to provide written informed consent, (2) currently comorbid with severe physical illness or intellectual disability that hindered the participants from completing the required mental evaluation, and (3) unable to be followed up in the long haul.

Once the patients met the inclusion criteria, a face-to-face interview was arranged by the study team member in charge of participant recruitment. Information about the off-label use of PP1M in BD, including the potential benefit and risk of this treatment, was told to all the potential participants and their custodians. Once agreement was achieved, written informed consent signed by both the participants and one of their custodians was provided. This study was reviewed and approved by the Clinical Research Ethics Committee of the Third Affiliated Hospital of Sun Yat-sen University.

\section{Treatment of the Participants}

PP1M was prescribed as monotherapy or adjunctive treatment by the participants' treating psychiatrists according to the patients' condition and willingness. Other psychopharmaceutical treatment was permitted before the administration of PP1M. Except the first two doses of PP1M were fixed (the first dose was $150 \mathrm{mg}$, and the second was $100 \mathrm{mg}$ ), the other doses of PP1M and the duration of PP1M treatment were flexibly decided by the participants' treating psychiatrists according to the patients' condition. In addition, any combined treatment, if necessary, was also decided by the treating psychiatrists.

\section{Evaluation of Baseline Clinical Characteristics of BD}

General sociodemographic and clinical characteristics, including the duration of illness, number of previous affective episodes, and duration of current episode, were collected via a questionnaire designed by the investigators. Physical comorbidities were collected by reviewing the patients' previous medical history and medical records stored in the electronic medical system. Severity of the illness were evaluated by the 17-item Hamilton Depression Scale (HAMD-17) (16), the Young Mania Rating Scale (YMRS) (17), and the Clinical Global Impression-Bipolar Scale (CGIBP) (18). Psychotic features were assessed by evaluating whether the participants demonstrated any of the psychotic symptoms, including hallucination, delusion, or disorganized behavior, in the course of illness. 


\section{Measurement of Efficacy and Safety Profile of the Treatment}

The efficacy of treatment was measured from the following aspects: compliance with pharmaceutical treatment, symptomatic improvement, prevention of relapse or switch to another polarized affective episode, prevention of hospitalization, control of disturbing behavior, and restore of employment.

Symptomatic improvement was evaluated by comparing the difference in the scores of HAMD-17, YMRS, and CGI$\mathrm{BP}$ between the baseline and the endpoint. CGI-BP was also measured at each injection of PP1M. Relapse or switch to the other polarized affective episode and hospitalization were monitored through the period of follow-up. Disturbing behavior was defined as any behavior that might threaten the patient's life, properties, and public order, including suicide attempt, fighting, destroying properties, harmful use of psychoactive substance, and so on. Status of employment was divided into three categories according to the participant's attendance in work or school: unemployment (which meant no attendance in work or school), part-time (which meant being partly involved in work or school), and full-time (which meant being fully involved in work or school). Disturbing behavior and status of employment were assessed at the baseline and the endpoint based on the past 1-month-related information. The safety of treatment was measured by Treatment Emergent Symptom Scale (TESS) at each study visit as a routine clinical assessment to assess any TEAEs. At the same time, any available results of laboratory examinations conducted during the period of follow-up would be reviewed to detect any potential treatment-related safety problem. The tolerability of PP1M was assessed by asking the reasons of treatment discontinuation if it happened.

\section{Definition of the Final Treatment Outcome}

The final treatment outcome is divided into three categories (19): relapse or switch, response, and remission. Relapse or switch is defined as a return or switch to the full syndrome criteria of an episode of mania, mixed episode, or depression following a remission of any duration. If relapse or switch is detected at any time during the period of follow-up, the final treatment outcome is categorized as relapse or switch, regardless of the scores of HAMD-17 or YMRS at the endpoint. Remission is defined as HAMD- $17<8$ and YRMS $<8$ at the endpoint, whereas no relapse or switch is detected during the period of follow-up. Response is defined as the 50\% reduction in the scores of HAMD or YRMS from the baseline to the endpoint while the other pole cannot be significantly worsened.

\section{Follow-Up}

The follow-up started from the first injection of PP1M. The follow-up visit was arranged at each injection of PP1M. If the PP1M treatment was not discontinued, the follow-up would go on until June 30, 2019. The final injection before treatment discontinuation or the last injection before June 30, 2019 was considered as the endpoint of the follow-up.

\section{Statistical Analysis}

The prevalence of discrete variables was calculated. Mean and standard deviation of normally distributed data were analyzed, whereas median and range from minimum to maximum were reported for non-normally distributed variables. Difference in the final treatment outcome between the groups was compared using Chi-square test. Mann-Whitney $U$-test was performed to compare the duration of follow-up between the different groups. The distribution of the scores of CGI-BP for all the participants was plotted using Microsoft Office Excel 2007 (Microsoft Corporation, Redmond, WA, United States). The results were considered significant at $P<0.05$. All data were analyzed using commercial statistical package SPSS 19.0 (SPSS, Inc., Chicago, IL, United States).

\section{RESULTS}

\section{Demographic and Clinical Characteristics of the Participants}

Eleven patients with BDI were eligible for this study; 10 (90.9\%) of them were recruited when being admitted to hospital. The demographic and clinical characteristics of the participants are listed in Table 1. Of the 11 participants, 5 (45.4\%) were female, their age ranged from 16 to 63 years with a median of 33 years, and $6(54.5 \%)$ were married. At the baseline, all the participants were in manic or mixed episodes, 7 (63.6\%) presented with psychotic features, 4 (36.4\%) experienced recent suicide attempts, $4(36.4 \%)$ were comorbid with abnormal glucose or lipid metabolism, $3(27.3 \%)$ had psychoactive substance abuse, 2 (18.2\%) were with thyroid diseases, their duration of illness ranged from 1 to 10 years with a median of 4 years, and $7(63.6 \%)$ had experienced at least one depressive episode, whereas all the participants had experienced at least one (hypo)manic/mixed episode.

\section{Treatment Information of the Participants}

The detailed information on the treatment of all the participants is listed in Table 2 . Nine $(81.8 \%)$ had received pharmaceutical treatment before the recruitment, with the time from the first dose of medication to recruitment ranging from 1 to 120 months. At the acute phase of treatment, only 3 (27.3\%) participants were treated with PP1M monotherapy, and the rest received combined treatment, including $2(18.2 \%)$ with modified electroconvulsive therapy (MECT). At the endpoint, 6 (54.5\%) participants maintained treatment with PP1M monotherapy, and the rest received concomitant lithium, alprazolam, or fluoxetine with PP1M treatment.

\section{Compliance With PP1M Treatment}

As seen in Table 2, up until June 30, 2019, 6 (54.5\%) participants discontinued the PP1M treatment. None of them was caused by adherence issue. Among the discontinuations, 4 (36.4\%) were attributed to efficacy reason, and $2(18.2 \%)$ were for personal reasons that were not associated with the medication itself. The median duration of treatment was 14 months, ranging from 5 to 22 months. 
TABLE 1 | The demographic and clinical characteristics of all the participants.

\begin{tabular}{|c|c|c|c|c|c|c|c|c|c|c|}
\hline No. & Age & Sex & $\begin{array}{l}\text { Marriage } \\
\text { status }\end{array}$ & $\begin{array}{l}\text { Current } \\
\text { episode }\end{array}$ & $\begin{array}{l}\text { Psychotic } \\
\text { feature }\end{array}$ & Comorbidity & $\begin{array}{l}\text { DI } \\
(y)\end{array}$ & NDE & NME & $\begin{array}{l}\text { DCE } \\
(\mathrm{m})\end{array}$ \\
\hline 1 & 37 & $\mathrm{~F}$ & Divorced & Manic & No & None & 1 & 1 & 3 & 3 \\
\hline 2 & 33 & M & Married & Mixed & Yes & Suicide attempt, nicotine dependence & 9 & 4 & 2 & 108 \\
\hline 3 & 16 & M & Unmarried & Mixed & Yes & Suicide attempt & 3 & 1 & 1 & 2 \\
\hline 4 & 27 & M & Married & Manic & Yes & $\begin{array}{l}\text { Obese, hepatic adipose infiltration, } \\
\text { Hashimoto's thyroiditis }\end{array}$ & 9 & 0 & 3 & 12 \\
\hline 5 & 63 & $\mathrm{~F}$ & Married & Manic & Yes & $\begin{array}{l}\text { Hepatic adipose infiltration, } \\
\text { hyperlipidemia, left middle cerebral } \\
\text { artery occlusion }\end{array}$ & 2 & 0 & 3 & 0.25 \\
\hline 6 & 20 & $\mathrm{~F}$ & Unmarried & Mixed & Yes & $\begin{array}{l}\text { Suicide attempt, alcohol abuse, } \\
\text { impaired glucose tolerance }\end{array}$ & 8 & 2 & 1 & 6 \\
\hline 7 & 26 & $\mathrm{~F}$ & Unmarried & Mixed & Yes & Acquired renal cyst & 9 & 5 & 4 & 0.07 \\
\hline 8 & 35 & $M$ & Married & Manic & Yes & Suicide attempt & 10 & 2 & 1 & 0.5 \\
\hline 9 & 38 & $M$ & Married & Mixed & No & None & 3 & 3 & 3 & 4 \\
\hline 10 & 33 & $\mathrm{~F}$ & Married & Manic & No & Arrhythmia, pneumonia, heart failure & 4 & 0 & 3 & 0.17 \\
\hline 11 & 23 & $M$ & Unmarried & Mixed & No & $\begin{array}{l}\text { Diabetes, hypothyroidism, nicotine } \\
\text { dependence }\end{array}$ & 3 & 0 & 1 & 48 \\
\hline
\end{tabular}

DI, duration of illness; NDE, number of depressive episode; NME, number of (hypo)manic or mixed episode; DCE, duration of current episode.

\section{Treatment Outcome of PP1M}

The treatment outcome of the 11 participants is illustrated in Table 3. The scores (mean \pm standard deviation) of HAMD-17, YMRS, and CGI-BP generally decreased from the baseline (16.1 $\pm 10.3,30.9 \pm 12.6,5.3 \pm 0.7)$ to the endpoint $(7.4 \pm 5.7,3.7 \pm$ $3.2,2.3 \pm 0.7)$. Figure 1 further illustrates the change of the scores of CGI-BP over each injection of PP1M. No new hospitalization happened to any of the participants during the period of PP1M treatment. Mild to moderate depressive episode $(8<$ HAMD$17<24$ or $2<$ CGI-BP $<5$ ) was detected among 3 cases $(27.3 \%)$ during the PP1M treatment, whereas no (hypo)manic episode was seen during the same period. At the endpoint, no disturbing behavior was detected, whereas it was seen in $10(90.9 \%)$ cases at the baseline. After PP1M treatment, only 1 case's status of employment (9.1\%) deteriorated from part-time schooling to suspension of schooling, the other cases' status of employment got improvement, including 4 (45.4\%) from unemployment to full-time work, 4 (45.4\%) from unemployment to part-time work, and $2(18.2 \%)$ from part-time work to full-time work.

\section{Comparison of the Final Treatment Outcome Between the PP1M Monotherapy Group and the PP1M Combined Treatment Group}

According to whether other psychopharmaceutical or MECT treatment was combined with PP1M at the baseline and at the endpoint, treatment group was divided into the initial/final PP1M monotherapy group and the initial/final PP1M combined therapy group. Chi-square test was performed to compare the final treatment outcome between the above-mentioned two groups, respectively. Duration of follow-up was also compared between the two groups using Mann-Whitney $U$ test. No significant difference in the final treatment outcome was found between the initial/final PP1M monotherapy group and the initial/final PP1M combined treatment group $(P>0.05)$. Duration of follow-up (median, minimum-maximum) was significantly longer in the final PP1M monotherapy group than in the final PP1M combined group (16.14-22 vs. 8.5-14) $(P=$ 0.009), but it did not significantly differ between the initial PP1M monotherapy group than in the initial PP1M combined group $(17.14-22$ vs. $12.5-18)(P>0.05)$.

\section{Safety of PP1M Treatment}

As seen in Table 4, the most common TEAE during PP1M treatment was sedation, reaching $63.6 \%$. Weight gain came next, with a prevalence of $54.5 \%$. The third rank TEAEs were prolactin-related adverse events, decreased energy, and insomnia, which shared the same prevalence of $45.5 \%$. The other less common TEAEs included depressive mood (27.3\%), extrapyramidal symptoms (EPS) (18.2\%), sickness (9.1\%), and injection-site pain (9.1\%).

\section{DISCUSSION}

In this prospective study, we enrolled $11 \mathrm{BD}$ patients who were prescribed PP1M as monotherapy or adjunctive treatment. The scores of HAMD-17, YMRS, and CGI-BP generally decreased from the baseline to the endpoint. All the disturbing behavior occurring at the entry was under control after treatment. Neither new hospitalization nor manic/mixed episode occurred during the period of PP1M treatment, whereas mild to moderate depressive episodes were reported in three cases. The status of employment improved among most of the cases, and no new safety concern was detected.

Speaking in terms of pharmacokinetics (20), PP1M provides consistent therapeutic plasma concentration over 4 weeks, eliminating the need for daily oral medication, and therefore 
TABLE 2 | Treatment of all the participants.

\begin{tabular}{|c|c|c|c|c|c|c|c|c|c|c|c|}
\hline No. & $\begin{array}{l}\text { Clinical } \\
\text { setting }\end{array}$ & $\begin{array}{l}\text { Medications before } \\
\text { PP1M }\end{array}$ & $\begin{array}{l}\text { TR } \\
(\mathrm{m})\end{array}$ & $\begin{array}{l}\text { Dose of } \\
\text { PP1M3 } \\
\text { (mg eq) }\end{array}$ & $\begin{array}{l}\text { Dose of } \\
\text { PP1Mf } \\
\text { (mg eq) }\end{array}$ & $\begin{array}{l}\text { Concomitant } \\
\text { treatment at the } \\
\text { acute phase }\end{array}$ & $\begin{array}{c}\text { Duration of } \\
\text { hospitalization } \\
\text { (d) }\end{array}$ & $\begin{array}{l}\text { Concomitant } \\
\text { medications at } \\
\text { the endpoint }\end{array}$ & $\begin{array}{l}\text { Discontinuation } \\
\text { of PP1M }\end{array}$ & $\begin{array}{l}\text { Reason for } \\
\text { discontinuation }\end{array}$ & $\begin{array}{l}\text { TD } \\
(\mathrm{m})\end{array}$ \\
\hline 1 & Inpatient & $\begin{array}{l}\text { Quetiapine, } \\
\text { sodium valproate, } \\
\text { estazolam }\end{array}$ & 1 & 100 & 75 & $\begin{array}{l}\text { Lithium ER } 0.6 / \mathrm{d} \text {, } \\
\text { benzhexol } 2 \mathrm{mg} \text { bid, } \\
\text { alprazolam } 0.4 \mathrm{mg} \text { bid, } \\
\text { MECT } 6 \text { courses }\end{array}$ & 17 & $\begin{array}{l}\text { Lithium 0.9/d, } \\
\text { alprazolam } 0.4 \mathrm{mg} / \mathrm{d}\end{array}$ & Yes & Depressive episode & 8 \\
\hline 2 & Inpatient & $\begin{array}{l}\text { Olanzapine } 10 \mathrm{mg} / \mathrm{d} \text {, } \\
\text { divalproex sodium 1.0/d }\end{array}$ & 3 & 100 & 75 & $\begin{array}{l}\text { Lithium ER } 0.9 / \mathrm{d} \text {, } \\
\text { benzhexol } 2 \mathrm{mg} \text { bid, } \\
\text { alprazolam } 0.4 \mathrm{mg} \text { qn }\end{array}$ & 7 & $\begin{array}{l}\text { Lithium } 1.2 / \mathrm{d} \text {, } \\
\text { alprazolam } 0.4 \mathrm{mg} \text { prn }\end{array}$ & Yes & Economic problem & 10 \\
\hline 3 & Inpatient & None & 0 & 150 & 75 & $\begin{array}{l}\text { Lithium } 0.9 / \mathrm{d} \text {, } \\
\text { Seroquel } 0.05 \text { qn }\end{array}$ & 16 & $\begin{array}{l}\text { Lithium 0.9/d, } \\
\text { fluoxetine } 10 \mathrm{mg} / \mathrm{d}\end{array}$ & Yes & Decreased motivation & 5 \\
\hline 4 & Inpatient & Aripiprazole 10 mg/d & 68 & 150 & 100 & None & 18 & None & No & & \\
\hline 5 & Inpatient & $\begin{array}{l}\text { Risperidone, } \\
\text { PP1M, } \\
\text { paliperidone ER, } \\
\text { sodium valproate, } \\
\text { benzhexol }\end{array}$ & 60 & 100 & 75 & $\begin{array}{l}\text { Lithium ER 0.9/d, } \\
\text { quetiapine } 100 \mathrm{mg} / \mathrm{d} \text {, } \\
\text { divalproex sodium } 1.0 / \mathrm{d} \text {, } \\
\text { ziprasidone injection } 40 \mathrm{mg} / \mathrm{d} \text {, } \\
\text { clonazepam } 1 \mathrm{mg} / \mathrm{d} \text {, } \\
\text { alprazolam } 0.4 \mathrm{mg} / \mathrm{d} \text {, } \\
\text { hydroclopidogrel } 75 \mathrm{mg} / \mathrm{d} \text {, } \\
\text { atorvastatin calcium } 10 \mathrm{mg} / \mathrm{d}\end{array}$ & 19 & $\begin{array}{l}\text { Hydroclopidogrel } \\
75 \mathrm{mg} / \mathrm{d} \text {, } \\
\text { atorvastatin calcium } \\
10 \mathrm{mg} / \mathrm{d}\end{array}$ & Yes & $\begin{array}{l}\text { Self-decided because } \\
\text { of decreased energy }\end{array}$ & 14 \\
\hline 6 & Inpatient & None & & 100 & 150 & $\begin{array}{l}\text { Quetiapine } 400 \mathrm{mg} / \mathrm{d} \text {, } \\
\text { oxcarbazepine 0.6/d, } \\
\text { lithium ER 0.9/d, } \\
\text { MECT } 9 \text { courses }\end{array}$ & 16 & None & No & & \\
\hline 7 & Inpatient & $\begin{array}{l}\text { Lamotrigine } 100 \mathrm{mg} / \mathrm{d} \text {, } \\
\text { clozapine } 300 \mathrm{mg} / \mathrm{d} \text {, } \\
\text { divalproex sodium 0.75/d, } \\
\text { lithium 1.0/d, } \\
\text { aripiprazole, } \\
\text { risperidone } 4 \mathrm{ml} / \mathrm{d}\end{array}$ & 34 & 100 & 100 & $\begin{array}{l}\text { Clozapine } 50 \mathrm{mg} / \mathrm{d} \text {, } \\
\text { aripiprazole } 5 \mathrm{mg} / \mathrm{d} \text {, } \\
\text { lithium } 0.5 / \mathrm{d}\end{array}$ & 9 & None & Yes & $\begin{array}{l}\text { Self-decided for plan to } \\
\text { get pregnant }\end{array}$ & 15 \\
\hline 8 & Inpatient & Clozapine & 120 & 100 & 75 & $\begin{array}{l}\text { Lithium ER } 1.2 / \mathrm{d} \text {, } \\
\text { clonazepam } 2 \mathrm{mg} / \mathrm{d}\end{array}$ & 14 & Lithium ER 0.9/d & Yes & Depressive mood & 6 \\
\hline 9 & Inpatient & $\begin{array}{l}\text { Paliperidone ER, } \\
\text { sodium valproate, } \\
\text { escitalopram }\end{array}$ & 36 & 100 & 75 & None & 16 & Lithium 0.6/d & No & & \\
\hline 10 & Inpatient t & $\begin{array}{l}\text { Divalproex sodium 0.75/d, } \\
\text { quetiapine } 500 \mathrm{mg} / \mathrm{d}\end{array}$ & 36 & 100 & 75 & $\begin{array}{l}\text { Divalproex sodium 0.75/d, } \\
\text { quetiapine } 600 \mathrm{mg} / \mathrm{d} \text {, } \\
\text { haldol } 20 \mathrm{mg} / \mathrm{d}(\mathrm{im}) \text {, } \\
\text { clozapine } 150 \mathrm{mg} / \mathrm{d}\end{array}$ & 14 & $\begin{array}{l}\text { Metformin 1.0/d, } \\
\text { atorvastatin calcium } \\
10 \mathrm{mg} / \mathrm{d}\end{array}$ & No & & \\
\hline 11 & Outpatient & Paliperidone ER & 5 & 150 & 150 & None & NA & None & No & & \\
\hline
\end{tabular}

TR, time from the first dose of medication to recruitment; PP1M3, the third injection of one-monthly paliperidone palmitate (PP1M); PP1Mf, the final injection of one-monthly paliperidone palmitate (PP1M); TD, time to discontinuation; NA, not applicable. 
TABLE 3 | Treatment outcome of all the participants.

\begin{tabular}{|c|c|c|c|c|c|c|c|c|c|c|c|c|c|c|}
\hline \multirow[t]{2}{*}{ No. } & \multicolumn{6}{|c|}{ Baseline } & \multirow{2}{*}{$\begin{array}{l}\text { DF } \\
(\mathrm{m})\end{array}$} & \multirow{2}{*}{$\begin{array}{l}\text { Relapse } \\
\text { or } \\
\text { switch }^{\text {b }}\end{array}$} & \multirow[t]{2}{*}{ Hospitalization $^{b}$} & \multicolumn{5}{|c|}{ Endpoint } \\
\hline & HAMD-17 & YMRS & NPH & CGI-BP & $\mathrm{SE}^{\mathrm{a}}$ & DB & & & & $\mathbf{D B}^{\mathrm{b}}$ & HAMD-17 & YMRS & CGI-BP & $\mathrm{SE}^{\mathrm{a}}$ \\
\hline 1 & 10 & 35 & 2 & 5 & 0 & $\begin{array}{l}\text { Running away from home } \\
\text { for no reason }\end{array}$ & 8 & 1 & 0 & 0 & 16 & 2 & 3 & 1 \\
\hline 2 & 31 & 31 & 0 & 6 & 0 & Aggressive behavior & 10 & 0 & 0 & 0 & 7 & 4 & 2 & 2 \\
\hline 3 & 28 & 14 & 0 & 5 & 1 & Suicide attempt & 5 & 1 & 0 & 0 & 15 & 7 & 3 & 0 \\
\hline 4 & 9 & 25 & 1 & 4 & 0 & Lavish spending & 22 & 0 & 0 & 0 & 3 & 5 & 2 & 2 \\
\hline 5 & 10 & 44 & 1 & 6 & 0 & Agitated behavior & 14 & 1 & 0 & 0 & 6 & 2 & 2 & 1 \\
\hline 6 & 29 & 31 & 0 & 6 & 1 & $\begin{array}{l}\text { Binge drinking, suicide } \\
\text { attempt, promiscuous sex }\end{array}$ & 18 & 0 & 0 & 0 & 1 & 1 & & 2 \\
\hline 7 & 19 & 25 & 2 & 5 & 0 & Fighting against her mother & 15 & 0 & 0 & 0 & 8 & 11 & 3 & 2 \\
\hline 8 & 5 & 51 & 0 & 6 & 0 & $\begin{array}{l}\text { Binge drinking, suicide } \\
\text { attempt, masturbation in } \\
\text { public }\end{array}$ & 6 & 1 & 0 & 0 & 15 & 3 & 3 & 1 \\
\hline 9 & 17 & 11 & 0 & 5 & 1 & No & 14 & 0 & 0 & 0 & 6 & 0 & 2 & 2 \\
\hline 10 & 0 & 46 & 2 & 6 & 0 & Aggressive behavior & 14 & 0 & 0 & 0 & 0 & 1 & 1 & 2 \\
\hline 11 & 19 & 27 & 0 & 5 & 0 & $\begin{array}{l}\text { Lavish spending, aggressive } \\
\text { behavior }\end{array}$ & 17 & 0 & 0 & 0 & 4 & 5 & 2 & 1 \\
\hline
\end{tabular}

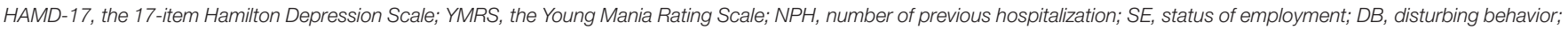
$D F$, duration of follow-up.

${ }^{a}$ 0, unemployment; 1, part-time employment; 2, full-time employment.

${ }^{b} 0$, no, 1 , yes.

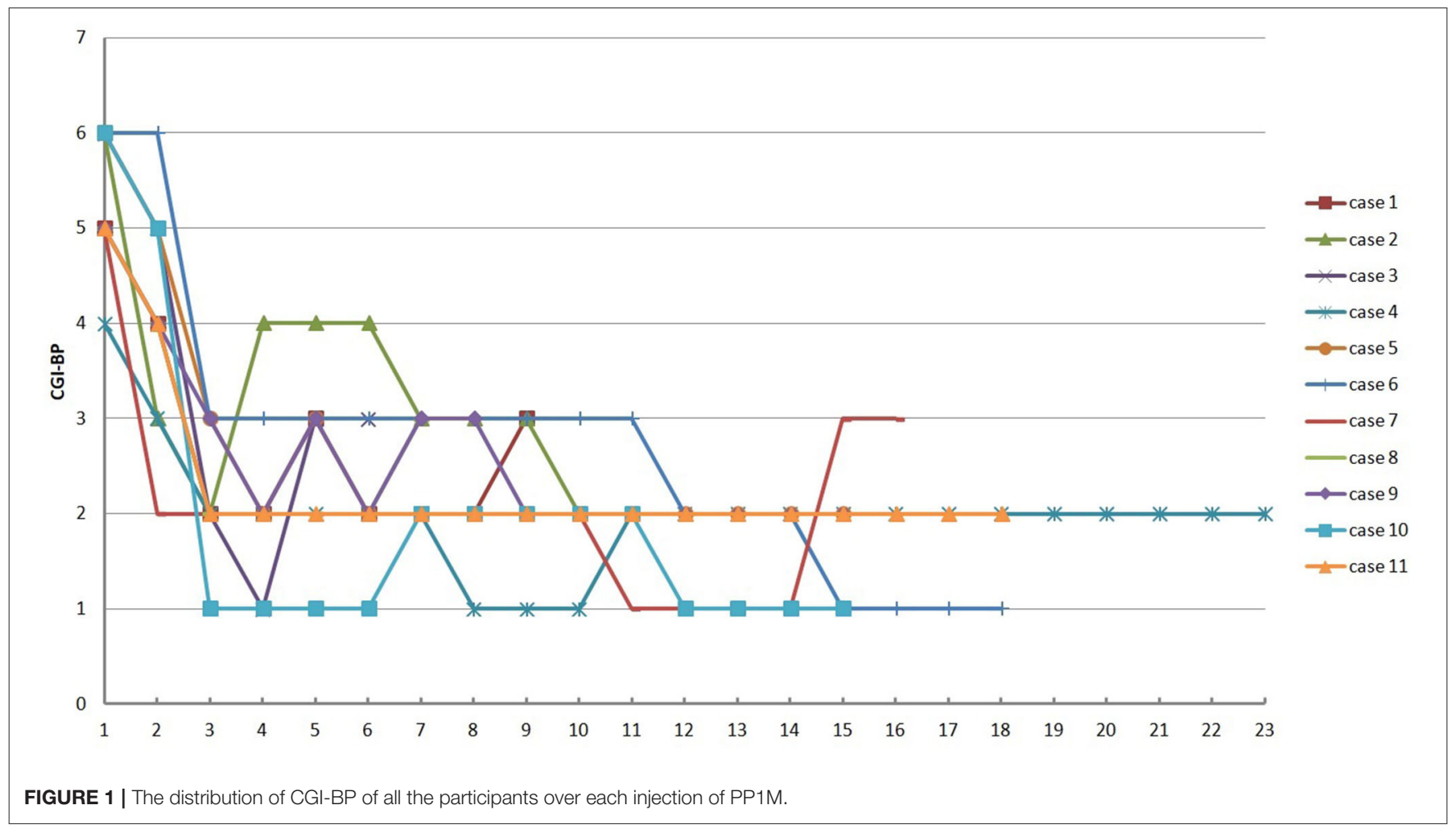

it helps to improve the treatment adherence. On contrary to the fact that most of the participants showed poor compliance with pharmaceutical treatment before PP1M was prescribed, all the participants in this study complied with the PP1M treatment as scheduled during the period of follow-up. This study supports this view in BD patients with poor compliance with pharmaceutical treatment, which is consistent with a previous case report that PP1M significantly improved the adherence to treatment among three psychotic BD patients who were not compliant with oral medication (21). Although previous randomized controlled trials (RCTs) did not find that long-acting injectable antipsychotics (LAIAs) were superior to 
TABLE 4 | The prevalence of adverse events during the treatment.

\begin{tabular}{|c|c|c|c|c|c|c|c|c|c|}
\hline \multirow[t]{2}{*}{ No. } & \multicolumn{9}{|c|}{ Adverse events $(\mathrm{AE})^{\mathrm{a}}$} \\
\hline & EPS & $\begin{array}{l}\text { Prolactin-related } \\
\text { AE }\end{array}$ & $\begin{array}{l}\text { Decreased } \\
\text { energy }\end{array}$ & Sedation & Sickness & $\begin{array}{l}\text { Weight } \\
\text { gain }\end{array}$ & Depressive mood & Insomnia & $\begin{array}{l}\text { Injection-site } \\
\text { pain }\end{array}$ \\
\hline 1 & 1 & 1 & 1 & 1 & 1 & 0 & 1 & 1 & 0 \\
\hline 2 & 1 & 0 & 0 & 0 & 0 & 0 & 0 & 1 & 0 \\
\hline 3 & 0 & 1 & 1 & 1 & 0 & 1 & 0 & 1 & 0 \\
\hline 4 & 0 & 1 & 0 & 0 & 0 & 1 & 0 & 0 & 0 \\
\hline 5 & 0 & 0 & 1 & 1 & 0 & 0 & 0 & 0 & 0 \\
\hline 6 & 0 & 0 & 0 & 1 & 0 & 0 & 0 & 0 & 0 \\
\hline 7 & 0 & 1 & 0 & 0 & 0 & 1 & 0 & 1 & 0 \\
\hline 8 & 0 & 0 & 1 & 1 & 0 & 1 & 1 & 1 & 0 \\
\hline 9 & 0 & 0 & 1 & 1 & 0 & 1 & 1 & 0 & 0 \\
\hline 10 & 0 & 1 & 0 & 1 & 0 & 1 & 0 & 0 & 1 \\
\hline 11 & 0 & 0 & 0 & 0 & 0 & 0 & 0 & 0 & 0 \\
\hline The prevalence of AE (\%) & 18.2 & 45.5 & 45.5 & 63.6 & 9.1 & 54.5 & 27.3 & 45.5 & 9.1 \\
\hline
\end{tabular}

EPS, extrapyramidal symptoms.

a 1 , occurred; 0 , not occurred.

oral corresponding medication in terms of compliance and rehospitalization rates, the highly compliant study populations in these studies might contribute to this negative result. In this study, all the participants had a history of non-compliance with medication or high risk of future non-compliance. Furthermore, some of them were undergoing a very severe manic episode, some experienced a recent suicide attempt, and others had comorbid psychoactive substance abuse. All these clinical characteristics were proven to be associated with non-compliance (22-26), preventing them from recruitment to any RCT study for ethical reasons. Therefore, our study adds to the evidence that PP1M may show advantage in treating BD patients with non-compliance, which usually could not be provided by RCT studies. In addition, PP1M seems to have some efficacy in the management of psychotic or non-psychotic BD in our study, which is consistent with previously demonstrated efficacy of paliperidone ER and PP1M in patients with current manic or mixed episodes, schizoaffective disorders (15), or psychotic BD (21). However, depressive episode was detected in three cases, suggesting that PP1M may be less effective in the prevention of depression, which is in line with the idea that depot neuroleptics showed better efficacy in preventing mania than depression (27). Combined with the fact that manic symptoms are more associated with non-compliance than depressive symptoms (28), $\mathrm{BD}$ with a predominance of manic symptoms may be more suitable to use PP1M.

The pattern of TEAEs in this study was similar to those previously reported in studies of PP1M in schizophrenia $(29,30)$, schizoaffective disorder $(15,31,32)$, and BD (21). In addition, no new safety concern was found, and no case was withdrawn from the PP1M treatment because of safety concern, suggesting that $\mathrm{PP} 1 \mathrm{M}$ is safe and tolerable in the long-term management of BD.

However, careful interpretation of the results from this study is needed because of some limitations. First, only 11 participants were included in this study. Such small sample size might dramatically weaken the capacity of this study's findings for generalization. Since most of the participants had a prominence of mania and were highly compliant with oral medication treatment, we cannot tell whether $\mathrm{BD}$ with a prominence of depression and high compliance would benefit from the PP1M treatment. Second, this study was an open-label, single-armed study, and combination of other treatment was allowable on several cases, especially at the acute phase. Third, in terms of clinical assessments, disturbing behavior, social function, and compliance were not usually assessed with standardized rating scale. Fourth, laboratory examinations were not always performed regularly, making some safety problem undetected. Large sample size, prospective standard controlled studies are needed in the future. Although with these limitations, the results presented here still show evidence that PP1M may be effective, safe, and tolerable in the long-term management of $\mathrm{BD}$ as monotherapy or adjunctive treatment. This effectiveness was demonstrated by the great improvement in the compliance to treatment, general decrease in the scores of HAMD, YMRS, and CGI, reduction in the number of mood episodes and hospitalization, and improvements in behaviors and social functions. More importantly, this effectiveness was unlikely to be due to placebo effect since 9 of the 11 participants had failed to response to active psychopharmaceutical treatment before. Nor could this effectiveness be completely attributed to the combined treatment, since no significant difference was found between the initial/final PP1M monotherapy group and the initial/final PP1M combined treatment group, and some combined treatment had been tried on some cases but failed to be complied with.

In summary, this small sample size study shows evidence that PP1M may be beneficial in the long-term management of BDI with a prominence of manic symptoms as monotherapy or adjunctive therapy. Especially in those with poor compliance 
with oral medication, PP1M may provide a new valid treatment option.

\section{DATA AVAILABILITY STATEMENT}

All datasets generated for this study are included in the article/supplementary material.

\section{ETHICS STATEMENT}

The studies involving human participants were reviewed and approved by the Clinical Research Ethics Committee of the Third Affiliated Hospital of Sun Yat-Sen University. Written informed consent to participate in this study was provided by the participants' legal guardian/next of kin. Written informed consent was obtained from the individual(s) for the publication of any potentially identifiable images or data included in this article.

\section{AUTHOR CONTRIBUTIONS}

ZG: conception and design. ZG and XW: recruitment of participants and clinical measurement. CY, ZY, MC, and

\section{REFERENCES}

1. Merikangas KR, Jin R, He JP, Kessler RC, Lee S, Sampson NA, et al. Prevalence and correlates of bipolar spectrum disorder in the world mental health survey initiative. Arch Gen Psychiatry. (2011) 68:24151. doi: 10.1001/archgenpsychiatry.2011.12

2. Schaffer A, Isometsa ET, Tondo L, Moreno DH, Sinyor M, Kessing LV, et al. Epidemiology, neurobiology and pharmacological interventions related to suicide deaths and suicide attempts in bipolar disorder: part I of a report of the International society for bipolar disorders task force on suicide in bipolar disorder. Aust N Z J Psychiatry. (2015) 49:785802. doi: $10.1177 / 0004867415594427$

3. Torres-Llenza V, Lakshmin P, Lieberman DZ. Spotlight on once-monthly long-acting injectable aripiprazole and its potential as maintenance treatment for bipolar I disorder in adult patients. Neuropsychiatr Dis Treat. (2018) 14:285-92. doi: 10.2147/NDT.S129559

4. Li K, Wei Q, Li G, He X, Liao Y, Gan Z. Time to lack of persistence with pharmacological treatment among patients with current depressive episodes: a natural study with 1-year follow-up. Patient Prefer Adherence. (2016) 10:220915. doi: 10.2147/PPA.S109941

5. Pezzin LE, Larson ER, Lorber W, McGinley EL, Dillingham TR. Music-instruction intervention for treatment of post-traumatic stress disorder: a randomized pilot study. BMC Psychol. (2018) 6:60. doi: 10.1186/s40359-018-0274-8

6. Hong J, Reed C, Novick D, Haro JM, Aguado J. Clinical and economic consequences of medication non-adherence in the treatment of patients with a manic/mixed episode of bipolar disorder: results from the European mania in bipolar longitudinal evaluation of medication (EMBLEM) study. Psychiatry Res. (2011) 190:110-4. doi: 10.1016/j.psychres.2011.04.016

7. Angst J, Angst F, Gerber-Werder R, Gamma A. Suicide in 406 mood-disorder patients with and without long-term medication: a 40 to 44 years' follow-up. Arch Suicide Res. (2005) 9:279-300. doi: 10.1080/13811110590929488

8. Gianfrancesco FD, Sajatovic M, Rajagopalan K, Wang RH. The association between treatment adherence and antipsychotic dose among individuals with bipolar disorder. Int Clin Psychopharmacol. (2008) 23:305-16. doi: 10.1097/YIC.0b013e32830b0f88
YL: management of treatment and follow-up. CY, ZY, and MC: collection and management of data. XW, CY, ZY, MC, and KL: analysis and interpretation of data. KL and YL: drafting the article. ZG: revising it for intellectual content. All authors contributed to the article and approved the submitted version.

\section{FUNDING}

Funding for this study was provided by the Science and Technology Program of Guangzhou (201609010086), the Third Affiliated Hospital of Sun Yat-sen University, Clinical Research Program, and the Natural Science Foundation of Guangdong Province, China (101510089010000214 and 2018A030313489). The above-mentioned funding bodies had no further role in the study design, collection, analysis, and interpretation of data, in the writing of the report, and in the decision to submit the paper for publication.

\section{ACKNOWLEDGMENTS}

The authors would like to gratefully acknowledge the contributions of all of the nurses, technicians, and patients who participated in this study.

9. Greene M, Yan T, Chang E, Hartry A, Touya M, Broder MS. Medication adherence and discontinuation of long-acting injectable versus oral antipsychotics in patients with schizophrenia or bipolar disorder. J Med Econ. (2018) 21:127-34. doi: 10.1080/13696998.2017.1379412

10. Vieta E, Nuamah IF, Lim P, Yuen EC, Palumbo JM, Hough DW, et al. A randomized, placebo-and active-controlled study of paliperidone extended release for the treatment of acute manic and mixed episodes of bipolar I disorder. Bipolar Disord. (2010) 12:230-43. doi: 10.1111/j.1399-5618.2010.00815.x

11. Berwaerts J, Lane R, Nuamah IF, Lim P, Remmerie B, Hough DW. Paliperidone extended-release as adjunctive therapy to lithium or valproate in the treatment of acute mania: a randomized, placebo-controlled study. J Affect Disord. (2011) 129:252-60. doi: 10.1016/j.jad.2010.09.011

12. Berwaerts J, Xu H, Nuamah I, Lim P, Hough D. Evaluation of the efficacy and safety of paliperidone extended-release in the treatment of acute mania: a randomized, double-blind, dose-response study. J Affect Disord. (2012) 136:e51-60. doi: 10.1016/j.jad.2010.06.030

13. Berwaerts J, Melkote R, Nuamah I, Lim P. A randomized, placebo-and activecontrolled study of paliperidone extended-release as maintenance treatment in patients with bipolar I disorder after an acute manic or mixed episode. $J$ Affect Disord. (2012) 138:247-58. doi: 10.1016/j.jad.2012.01.047

14. Yatham LN, Kennedy SH, Parikh SV, Schaffer A, Bond DJ, Frey BN, et al. Canadian network for mood and anxiety treatments (CANMAT) and International society for bipolar disorders (ISBD) 2018 guidelines for the management of patients with bipolar disorder. Bipolar Disord. (2018) 20:97170. doi: 10.1111/bdi.12609

15. Fu DJ, Turkoz I, Simonson RB, Walling DP, Schooler NR, Lindenmayer JP, et al. Paliperidone palmitate once-monthly reduces risk of relapse of psychotic, depressive, and manic symptoms and maintains functioning in a doubleblind, randomized study of schizoaffective disorder. J Clin Psychiatry. (2015) 76:253-62. doi: 10.4088/JCP.14m09416

16. Hamilton M. A rating scale for depression. J Neurol Neurosurg Psychiatry. (1960) 23:56-62. doi: 10.1136/jnnp.23.1.56

17. Young RC, Biggs JT, Ziegler VE, Meyer DA. A rating scale for mania: reliability, validity and sensitivity. Br J Psychiatry. (1978) 133:42935. doi: 10.1192/bjp.133.5.429 
18. Spearing MK, Post RM, Leverich GS, Brandt D, Nolen W. Modification of the clinical global impressions (CGI) Scale for use in bipolar illness (BP): the CGIBP. Psychiatry Res. (1997) 73:159-71. doi: 10.1016/S0165-1781(97)00123-6

19. Hirschfeld RM, Calabrese JR, Frye MA, Lavori PW, Sachs G, Thase ME, et al. Defining the clinical course of bipolar disorder: response, remission, relapse, recurrence, and roughening. Psychopharmacol Bull. (2007) 40:7-14.

20. Hoy SM, Scott LJ, Keating GM. Intramuscular paliperidone palmitate. CNS Drugs. (2010) 24:227-44. doi: 10.2165/11203810-000000000-00000

21. Buoli M, Ciappolino V, Altamura AC. Paliperidone palmitate depot in the long-term treatment of psychotic bipolar disorder: a case series. Clin Neuropharmacol. (2015) 38:209-11. doi: 10.1097/WNF.0000000000000103

22. Oquendo MA, Currier D, Liu S, Hasin D, Grant B, Blanco C. Increased risk for suicidal behavior in comorbid bipolar disorder and alcohol use disorders. J Clin Psychiatry. (2010) 71:902-9. doi: 10.4088/JCP.09m05198gr

23. Baldessarini RJ, Perry R, Pike J. Factors associated with treatment nonadherence among US bipolar disorder patients. Hum Psychopharmacol. (2008) 23:95-105. doi: 10.1002/hup.908

24. Perlis RH, Ostacher MJ, Miklowitz DJ, Hay A, Nierenberg AA, Thase ME, et al. Clinical features associated with poor pharmacologic adherence in bipolar disorder: results from the STEP-BD study. J Clin Psychiatry. (2010) 71:296-303. doi: 10.4088/JCP.09m05514yel

25. Sajatovic M, Levin JB, Sams J, Cassidy KA, Akagi K, Aebi ME, et al. Symptom severity, self-reported adherence, and electronic pill monitoring in poorly adherent patients with bipolar disorder. Bipolar Disord. (2015) 17:653-61. doi: 10.1111/bdi.12326

26. Martinez-Aran A, Scott J, Colom F, Torrent C, Tabares-Seisdedos R, Daban $\mathrm{C}$, et al. Treatment nonadherence and neurocognitive impairment in bipolar disorder. J Clin Psychiatry. (2009) 70:1017-23. doi: 10.4088/JCP.08m04408

27. Pacchiarotti I, Tiihonen J, Kotzalidis GD, Verdolini N, Murru A, Goikolea JM, et al. Long-acting injectable antipsychotics (LAIs) for maintenance treatment of bipolar and schizoaffective disorders: a systematic review. Eur Neuropsychopharmacol. (2019) 29:457-70. doi: 10.1016/j.euroneuro.2019.02.003
28. Sylvia LG, Reilly-Harrington NA, Leon AC, Kansky CI, Calabrese JR, Bowden $\mathrm{CL}$, et al. Medication adherence in a comparative effectiveness trial for bipolar disorder. Acta Psychiatr Scand. (2014) 129:359-65. doi: 10.1111/acps.12202

29. Choon JWY, Wu DBC, Chong HY, Lo WTL, Chong CSY, Chung WS, et al. Real-world evidence of improved healthcare utilization in patients with schizophrenia or schizoaffective disorder after early treatment of paliperidone palmitate once-monthly treatment in Hong Kong. J Med Econ. (2019) 22:2739. doi: 10.1080/13696998.2018.1560749

30. Si T, Zhuo J, Turkoz I, Mathews M, Tan W, Feng Y. Once-monthly injection of paliperidone palmitate in patients with recently diagnosed and chronic schizophrenia: a post-hoc comparison of efficacy and safety. Expert Opin Pharmacother. (2017) 18:1799-1809. doi: 10.1080/14656566.2017.1401608

31. Fu DJ, Turkoz I, Walling D, Lindenmayer JP, Schooler NR, Alphs L. Paliperidone palmitate once-monthly maintains improvement in functioning domains of the personal and social performance scale compared with placebo in subjects with schizoaffective disorder. Schizophr Res. (2018) 192:18593. doi: 10.1016/j.schres.2017.04.004

32. Bossie CA, Turkoz I, Alphs L, Mahalchick L, Fu DJ. Paliperidone palmitate once-monthly treatment in recent onset and chronic illness patients with schizoaffective disorder. J Nerv Ment Dis. (2017) 205:32428. doi: 10.1097/NMD.0000000000000646

Conflict of Interest: The authors declare that the research was conducted in the absence of any commercial or financial relationships that could be construed as a potential conflict of interest.

Copyright (C) 2021 Li, Liao, Yang, Yang, Chen, Wu and Gan. This is an open-access article distributed under the terms of the Creative Commons Attribution License (CC $B Y)$. The use, distribution or reproduction in other forums is permitted, provided the original author(s) and the copyright owner(s) are credited and that the original publication in this journal is cited, in accordance with accepted academic practice. No use, distribution or reproduction is permitted which does not comply with these terms. 